\title{
Antipsychotic Medication Utilization in Nonpsychiatric Hospitalizations
}

\author{
Shoshana J. Herzig, MD, MPH',2*, Michael B. Rothberg, MD, MPH³, Jamey R. Guess, MS¹, Jerry H. Gurwitz, MD, \\ Edward R. Marcantonio, MD, SM $1,2,6$
}

\begin{abstract}
${ }^{1}$ Division of General Medicine and Primary Care, Beth Israel Deaconess Medical Center, Boston, Massachusetts; ${ }^{2 H a r v a r d ~ M e d i c a l ~ S c h o o l, ~ B o s t o n, ~}$ Massachusetts; ${ }^{3}$ Center for Value-Based Care Research, Medicine Institute, Cleveland Clinic, Cleveland, Ohio; ${ }^{4}$ Meyers Primary Care Institute, A Joint Endeavor of University of Massachusetts Medical School, Reliant Medical Group, and Fallon Health, Worcester, Massachusetts; ${ }^{5}$ University of Massachusetts Medical School, Worcester, Massachusetts; 'Division of Gerontology, Beth Israel Deaconess Medical Center, Boston, Massachusetts.
\end{abstract}

BACKGROUND: Although antipsychotics are used for treatment of delirium/agitation in hospitalized patients, their scope of use has not been investigated in a large, multicenter cohort.

OBJECTIVE: To determine rates of use and hospital variation in use of antipsychotics in nonpsychiatric admissions.

DESIGN, SETTING, PATIENTS: Cohort study of adult, nonpsychiatric admissions to 300 US hospitals contributing data to the Premier database, from July 1, 2009 to June 30, 2010.

MEASUREMENTS: Antipsychotic exposure defined using pharmacy charges. Potentially excessive dosing defined using guidelines for long-term care facilities.

RESULTS: Our cohort included 2,695,081 admissions (median age, 63 years; 56\% female). Antipsychotic exposure occurred in 160,773 (6\%) admissions; 102,148 (64\%) received atypical antipsychotics, 76,979 (48\%) received typical, and 18,354 (11\%) received both. Among exposed admissions, $47 \%$ received $\geq 1$ potentially excessive daily dose. Among the variables we analyzed, the strongest predictors of antipsychotic receipt were delirium (relative risk [RR]: 2.93, 95\% Cl: 2.88-2.98) and dementia (RR: 2.78, $95 \% \mathrm{Cl}: 2.72-2.83)$. After adjustment for patient characteristics, patients admitted to hospitals in the highest antipsychotic prescribing quintile were more than twice as likely to be exposed compared to patients admitted to hospitals in the lowest prescribing quintile (RR: $2.56,95 \% \mathrm{Cl}: 2.50-$ 2.61). This relationship was similar across subgroups of admissions with delirium and dementia.

CONCLUSIONS: Antipsychotic medication exposure is common in nonpsychiatric admissions to US hospitals. The observed variation in antipsychotic prescribing was not fully explained by measured patient characteristics, suggesting the possibility of differing hospital prescribing cultures. Additional research and guidelines are necessary to define appropriate use of these potentially harmful medications in the hospital setting. Journal of Hospital Medicine 2016;11:543-549. (C) 2016 Society of Hospital Medicine

Because variation in practice is known to increase in the setting of controversy or lack of clarity regarding appropriate management, ${ }^{5}$ large degrees of variation can draw attention to priority areas for clinical effectiveness studies, and the need for guidelines, clinical decision support, or regulatory oversight. In the absence of clear guidelines for the use of antipsychotic medication in nonpsychiatric hospitalized patients, we hypothesized that significant variation in use would persist after controlling for patient characteristics. Using a large, nationally representative cohort of admissions to 300 hospitals from July 2009 to June 2010, we sought to investigate prescribing patterns and hospital variation in use of antipsychotic medications in nonpsychiatric admissions to US hospitals.

\section{METHODS}

\section{Setting and Data Collection}

We conducted a retrospective cohort study using data from 300 US, nonfederal, acute care facilities contributing to the database maintained by Premier (Premier Healthcare Solutions, Inc., Charlotte, NC). This nationally representative database, created to measure healthcare utilization and quality of care, is drawn from voluntarily participating hospitals and contains 
data on approximately 1 in every 4 discharges nationwide. ${ }^{6}$ Participating hospitals are similar in geographic distribution and urban/rural status to hospitals nationwide, although large, nonteaching hospitals are slightly over-represented. The study was approved by the institutional review board at Beth Israel Deaconess Medical Center.

\section{Inclusion and Exclusion Criteria}

We studied a cohort of all adult ( $\geq 18$ years) nonpsychiatric admissions to participating hospitals from July 1, 2009 through June 30, 2010. We excluded patients admitted to a psychiatry service or with any discharge diagnosis of a psychotic disorder (defined by the Elixhauser comorbidity "Psychoses:" 295.00298.9, 299.10-299.11), because we were interested in use of antipsychotics for conditions other than primary psychiatric disorders. We also excluded patients with a charge for "labor and delivery" owing to the nonrepresentativeness of this patient population for the general hospitalized patient. We excluded admissions with unknown gender, and admissions with a length of stay greater than 365 days, as these admissions are not representative of the typical admission to an acute care hospital. We also excluded hospitals contributing less than 100 admissions owing to lack of precision in corresponding hospital prescribing rates.

\section{Antipsychotic Medication Utilization}

In-hospital antipsychotic use was ascertained from pharmacy charges, reflecting each medication dispensed during the hospitalization. We categorized antipsychotic medications as typical (haloperidol, loxapine, thioridazine, molindone, thiothixine, pimozide, fluphenazine, trifluoperazine, chlorpromazine, and perphenazine) and atypical (aripiprazole, asenapine, clozapine, iloperidone, lurasidone, olanzapine, paliperidone, quetiapine, risperidone, and ziprasidone) based on classification by the Food and Drug Administration. ${ }^{7,8}$ We excluded prochlorperazine (Compazine) from our typical antipsychotic definition, as this medication is almost exclusively used as an antiemetic.

In the absence of guidelines for use of antipsychotic agents in hospitalized patients, we used the Centers for Medicare and Medicaid Services (CMS) guidelines for long-term care facilities to define measures of potentially excessive dosing in the hospital setting. ${ }^{9}$ These guidelines define the daily dosage levels of antipsychotics above which the medical necessity of the higher dose should be explained in the medical record. We defined any daily dosage above these specified levels as a "potentially excessive daily dose."

\section{Characteristics Associated With Use}

We investigated the association between antipsychotic use and patient and hospital characteristics, selected based on clinical grounds. Patient characteristics included: (1) demographic variables such as age $(<65$, $65-74,75+$ years), gender, self-reported race, marital status, and primary insurance; (2) admission characteristic variables, including admitting department (surgical vs nonsurgical, defined by a surgical attending of record and presence of operating room charges), whether the patient spent any time in the intensive care unit (ICU), and whether they received mechanical ventilation; and (3) potential indications for use, including delirium (included delirium superimposed upon dementia), dementia (without delirium), and insomnia (see Supporting Information, Appendix, in the online version of this article for International Classification of Diseases, Ninth Revision, Clinical Modification [ICD-9-CM] codes). Hospital characteristics included number of beds, urban versus rural status, teaching status, and US Census region.

\section{Statistical Analysis}

We report the proportion of admissions with inhospital use of any antipsychotic, and the number of days of exposure, overall and stratified by typical and atypical.

We determined potentially excessive dosing by taking the sum of the doses for a specific antipsychotic charged on a given day and comparing it to the CMS guidelines for long-term care settings described above. We report the percentage of exposed admissions with at least 1 day of potentially excessive dosing.

All multivariable models below were operationalized as generalized estimating equations with a Poisson error term, log link, robust variance estimator, ${ }^{10}$ and an exchangeable correlation structure to account for repeated admissions of the same patient.

We investigated patient and hospital characteristics associated with use of any antipsychotic medication using a multivariable model that simultaneously included all patient and hospital characteristics in Table 1 as independent variables.

To determine hospital variation in antipsychotic use, we first determined the proportion of admissions at each hospital with at least 1 charge for antipsychotic medication. We then divided hospitals into quintiles based on their facility-level antipsychotic prescribing rates and assigned all admissions to their corresponding hospital quintile. We then used a multivariable model to measure the adjusted association between prescribing quintile and patient-level receipt of antipsychotic medication, controlling for all patient characteristics listed in Table 1 (except discharge disposition), and comorbidities using the Healthcare Cost and Utilization Project Comorbidity Software version 3.7 (Agency for Healthcare Research and Quality, Rockville, MD). ${ }^{11}$ We used the lowest prescribing quintile as the reference group. We also report in the Supporting Information, Appendix, in the online version of this article, the distribution of prescribing rates for the hospitals in our cohort before 
TABLE 1. Characteristics of the Cohort and Rates of Antipsychotic Exposure by Characteristic

$(\mathrm{N}=2,695,081)^{\star}$

\begin{tabular}{|c|c|c|c|c|}
\hline & $\begin{array}{c}\% \text { of } \\
\text { Cohort }\end{array}$ & $\begin{array}{c}\text { Any } \\
\text { Exposure, \% }\end{array}$ & $\begin{array}{c}\text { Typical } \\
\text { Exposure, } \% \dagger\end{array}$ & $\begin{array}{c}\text { Atypical } \\
\text { Exposure, } \% \dagger\end{array}$ \\
\hline \multicolumn{5}{|l|}{ Patient characteristics } \\
\hline \multicolumn{5}{|l|}{ Age group, y } \\
\hline$<65$ & 52.1 & 4.6 & 2.0 & 3.1 \\
\hline $65-74$ & 18.5 & 5.2 & 2.7 & 3.1 \\
\hline $75+$ & 29.4 & 8.8 & 4.6 & 5.4 \\
\hline \multicolumn{5}{|l|}{ Gender } \\
\hline Male & 43.8 & 6.6 & 3.6 & 3.8 \\
\hline Female & 56.2 & 5.5 & 2.3 & 3.8 \\
\hline \multicolumn{5}{|l|}{ Race } \\
\hline White & 64.6 & 6.1 & 2.9 & 4.0 \\
\hline Black & 13.5 & 5.5 & 2.8 & 3.3 \\
\hline Hispanic & 5.0 & 4.9 & 2.2 & 3.2 \\
\hline Other & 19.9 & 6.1 & 3.1 & 3.7 \\
\hline \multicolumn{5}{|l|}{ Marital Status } \\
\hline Married & 42.5 & 4.6 & 2.4 & 2.7 \\
\hline Single & 46.7 & 7.2 & 3.2 & 4.7 \\
\hline Unknown/other & 10.8 & 6.4 & 3.1 & 4.1 \\
\hline \multicolumn{5}{|l|}{ Primary insurance } \\
\hline Private (commercial) & 28.8 & 3.0 & 1.5 & 1.8 \\
\hline Medicaid & 10.3 & 6.4 & 2.4 & 4.6 \\
\hline Medicare managed & 10.6 & 7.1 & 4.1 & 4.0 \\
\hline Medicare traditional & 40.9 & 8.0 & 3.7 & 5.3 \\
\hline Self-pay or other & 9.4 & 4.3 & 2.5 & 2.2 \\
\hline \multicolumn{5}{|l|}{ Admitting department } \\
\hline Surgical & 60.6 & 5.8 & 3.1 & 3.4 \\
\hline Nonsurgical & 39.4 & 6.2 & 2.4 & 4.4 \\
\hline Any ICU stay & 16.6 & 10.4 & 7.2 & 4.9 \\
\hline Mechanical ventilation & 4.7 & 17.4 & 12.9 & 7.9 \\
\hline \multicolumn{5}{|l|}{ Diagnoses } \\
\hline Delirium & 3.2 & 28.6 & 19.4 & 15.7 \\
\hline Dementia & 3.1 & 27.4 & 12.0 & 20.2 \\
\hline Insomnia & 1.3 & 10.2 & 3.9 & 7.5 \\
\hline \multicolumn{5}{|l|}{ Discharge disposition } \\
\hline Home & 77.9 & 3.8 & 1.6 & 2.5 \\
\hline SNF/Rehab & 15.5 & 13.7 & 6.8 & 9.0 \\
\hline Hospice & 1.7 & 16.0 & 10.3 & 8.1 \\
\hline Other & 4.9 & 11.6 & 7.6 & 5.7 \\
\hline \multicolumn{5}{|l|}{ Hospital characteristics, \% } \\
\hline \multicolumn{5}{|l|}{ No. of beds } \\
\hline$\leq 200$ & 14.1 & 6.1 & 2.8 & 3.8 \\
\hline $201-300$ & 18.6 & 6.1 & 2.9 & 3.9 \\
\hline $301-500$ & 37.7 & 5.9 & 2.9 & 3.7 \\
\hline $500+$ & 29.7 & 5.9 & 2.8 & 3.8 \\
\hline \multicolumn{5}{|l|}{ Population served } \\
\hline Urban & 89.4 & 6.0 & 2.9 & 3.8 \\
\hline Rural & 10.6 & 5.8 & 2.4 & 3.9 \\
\hline \multicolumn{5}{|l|}{ Teaching status } \\
\hline Teaching & 39.2 & 5.8 & 2.9 & 3.7 \\
\hline Nonteaching & 60.8 & 6.0 & 2.8 & 3.9 \\
\hline \multicolumn{5}{|l|}{ US Census region } \\
\hline West & 16.9 & 5.9 & 3.2 & 3.5 \\
\hline Northeast & 20.1 & 6.1 & 2.9 & 3.9 \\
\hline Midwest & 21.9 & 5.7 & 2.5 & 3.8 \\
\hline South & 41.0 & 6.1 & 2.9 & 3.9 \\
\hline
\end{tabular}

NOTE: Abbreviations: ICU, intensive care unit; SNF, skilled nursing facility. ${ }^{*} P$ values were not calculated owing to the large size of the dataset and resultant uniform statistical significance. †The sum of the percent exposed to typical and the percent exposed to atypical may exceed the percent with any antipsychotic exposure, because some patients were exposed to both typical and atypical antipsychotics during the hospitalization.

and after adjustment for patient characteristics. For both approaches, we conducted stratified analyses in admissions with delirium and dementia.
All analyses were carried out using SAS software (SAS Institute Inc., Cary, NC).

\section{RESULTS \\ Admission Characteristics}

There were 3,190,934 admissions aged 18 years and over to 300 hospitals from July 1, 2009 to June 30, 2010. After excluding admissions with unknown gender $(\mathrm{n}=17)$, length of stay greater than 365 days ( $\mathrm{n}$ $=25)$, charges for labor and delivery $(\mathrm{n}=323,111)$ or a psychiatric attending of record or psychiatric comorbidity $(\mathrm{n}=172,669)$, and admissions to hospitals with fewer than 100 admissions ( $\mathrm{n}=31$ ), our cohort included 2,695,081 admissions. The median age was 63 years (25th, 75 th percentile 48,77 years), and $1,514,986(56 \%)$ were women. Table 1 shows the overall admission characteristics of the cohort and the percent exposed to antipsychotics among each patient and hospital characteristic.

\section{Antipsychotic Use}

There were $160,773(6 \%)$ admissions with antipsychotic exposure. Among exposed admissions, 102,148 $(64 \%)$ received atypical and $76,979(48 \%)$ received typical antipsychotics, with $18,354(11 \%)$ exposed to both. The median (25th, 75 th percentile) length of stay among exposed was 5 days (3,9 days), and the median (25th, 75th percentile) number of days of exposure was 3 (1, 5 days) overall, 3 days (2, 6 days) for atypical and 2 days (1, 3 days) for typical exposure.

Among admissions aged 65 to 74 years, 25,855 $(5 \%)$ were exposed. Among admissions aged 75 years or older, 69,792 (9\%) were exposed. Among admissions with delirium, exposure occurred in 24,787 $(29 \%)$, with $13,640(55 \%)$ receiving atypical, 16,828 $(68 \%)$ receiving typical, and $5681(23 \%)$ exposed to both. Among admissions with dementia, exposure occurred in $23,179(27 \%)$, with $17,068(74 \%)$ receiving atypical, 10,108 (44\%) receiving typical, and 3997 (17\%) exposed to both.

\section{Use of Specific Drugs and Potentially Excessive Dosing}

Table 2 demonstrates the most commonly used antipsychotic medications and the rates of potentially excessive dosing. Quetiapine and olanzapine were the most commonly used atypical antipsychotics, and haloperidol represented the majority of typical antipsychotic use. Among admissions with antipsychotic exposure, $47 \%$ received at least 1 potentially excessive daily dose, $18 \%$ of those with atypical exposure and $79 \%$ of those with typical exposure. Among admissions aged 65 years and up $(\mathrm{n}=1,291,375)$, the prevalence of potentially excessive dosing was almost identical; $46 \%$ received at least 1 daily dose in excess of the recommended daily dose, $11 \%$ of those with 
TABLE 2. Prevalence of Antipsychotic Use and Percent of Exposed With At Least One Day of Potentially Excessive Dosing* $^{*}$

\begin{tabular}{|c|c|c|c|c|}
\hline \multirow[b]{2}{*}{ Agent $\dagger$} & \multirow{2}{*}{$\begin{array}{l}\text { Overall Prevalence, } \\
\qquad N=2,695,081\end{array}$} & \multicolumn{3}{|c|}{ \% of Exposed With Potentially Excessive Dosing* } \\
\hline & & Within $100 \%$ of Recommended DD* & $101 \%$ to $150 \%$ of Recommended DD* & $>150 \%$ of Recommended DD* \\
\hline Any antipsychotic & 6.0 & 52.9 & 20.2 & 26.9 \\
\hline Atypical & 3.8 & 82.0 & 5.4 & 12.6 \\
\hline Quetiapine (200) & 1.8 & 81.7 & 5.7 & 12.6 \\
\hline Olanzapine (10) & 0.6 & 73.7 & 7.3 & 19.0 \\
\hline Risperidone (2) & 0.9 & 79.2 & 6.8 & 14.0 \\
\hline Other & 0.7 & 98.3 & 0.1 & 1.6 \\
\hline Typical & 2.9 & 21.1 & 37.0 & 41.9 \\
\hline Haloperidol (4) & 2.5 & 13.2 & 41.3 & 45.5 \\
\hline Chlorpromazine (75) & 0.3 & 76.0 & 9.8 & 14.2 \\
\hline Other & 0.4 & 89.1 & 2.9 & 8.0 \\
\hline
\end{tabular}

NOTE: Abbreviations: CMS, Centers for Medicare and Medicaid Services; DD, daily dose. *Defined by the CMS guidelines for long-term care facilities. †Numbers in parentheses represent the recommended daily dose above which use should be justified based on the CMS guidelines for long-term care facilities.

atypical exposure and $79 \%$ of those with typical exposure.

\section{Characteristics Associated With Antipsychotic Use}

Among the patient and hospital characteristics included in our analysis, the 5 characteristics most strongly associated with antipsychotic exposure after adjustment were (Table 3): delirium (relative risk [RR]: 2.93, 95\% confidence interval [CI]: 2.88-2.98); dementia (RR: 2.78, 95\% CI: 2.72-2.83); insurance status, with higher risk among patients with traditional Medicare (RR: 2.09, 95\% CI: 2.04-2.13), Medicare managed (RR: 1.98, 95\% CI: 1.93-2.03), Medicaid (RR: 1.84, 95\% CI: 1.80-1.88), and selfpay/other (RR: $1.26,95 \%$ CI: 1.23-1.29) compared to private (commercial) insurance; use of mechanical ventilation (RR: 1.84, 95\% CI: 1.81-1.87); and any ICU stay (RR: 1.53, 95\% CI: 1.51-1.55).

\section{Hospital Variation in Antipsychotic Use}

Figure 1 demonstrates the antipsychotic prescribing rate at each hospital in our cohort, and the corresponding quintiles. Patients admitted to hospitals in the highest prescribing quintile were more than twice as likely to be exposed to antipsychotics compared to patients admitted to hospitals in the lowest prescribing quintile, even after adjustment for patient characteristics and comorbidities (Table 4). This relationship was similar across subgroups of admissions with delirium and dementia (see Supporting Information, Appendix, in the online version of this article for the distribution of hospital antipsychotic prescribing rates before and after adjustment for patient characteristics).

\section{DISCUSSION}

In this cohort of nonpsychiatric admissions to 300 US hospitals, antipsychotic medications were used in $6 \%$ of admissions, with atypical antipsychotics representing the majority of use. Potentially excessive daily doses based on CMS recommendations for long-term care facilities occurred in almost half of admissions with any antipsychotic exposure, and in $87 \%$ of admissions with haloperidol exposure specifically. We found variation in hospital use of antipsychotics that was not fully accounted for by measured patient characteristics, and which persisted among subgroups of admissions with delirium and/or dementia. Although unmeasured patient characteristics or different billing practices between hospitals are potential explanations, our findings also raise the possibility of different hospital antipsychotic prescribing cultures. These findings provide new information regarding the scope of prescribing in US hospitals, and draw attention to the need for additional studies to better define what constitutes appropriate use of antipsychotics in the hospital setting.

A recent single-center study at a large academic medical center found an overall antipsychotic exposure rate of $9 \%$ of nonpsychiatric admissions. ${ }^{12}$ Our finding that $6 \%$ of admissions in this multicenter cohort were exposed to antipsychotics is slightly lower, but similar to the previous estimate. Assuming 37 million discharges from US hospitals each year, ${ }^{13}$ our study suggests that more than 2 million hospitalized patients receive antipsychotics annually. With around 1.4 million residents in nursing homes on any given day, ${ }^{14}$ and an exposure rate of $25 \%$ to $30 \%$ in that setting, ${ }^{15-17}$ our study suggests that the number of patients exposed in the hospital setting is greater than the number exposed in the nursing home setting, the site of care for which prescribing regulations have been focused thus far.

Because our dataset does not contain preadmission medications, we were unable to specifically investigate new initiation. In the prior single-center study, approximately $55 \%$ of overall use in the hospital setting was new initiation, ${ }^{12}$ which would suggest that antipsychotics are newly initiated in around 1 million admissions each year in the hospital. Although we are unable to determine reason for use in our analysis, delirium was a strong predictor of antipsychotic use in our multivariable model, and prior studies have 
TABLE 3. Risk of Any Antipsychotic Exposure $(\mathrm{N}=2,695,081)$

\begin{tabular}{|c|c|c|}
\hline & $\begin{array}{l}\text { Unadjusted RR of Receiving } \\
\text { Any Antipsychotic [95\% Cl] }\end{array}$ & $\begin{array}{l}\text { Adjusted RR of Receiving } \\
\text { Any Antipsychotic }[95 \% \mathrm{Cl}]^{*}\end{array}$ \\
\hline \multicolumn{3}{|l|}{ Age group, y, \% } \\
\hline$<65$ & Reference & Reference \\
\hline $65-74$ & $1.12[1.10,1.14]$ & $0.74[0.72,0.75]$ \\
\hline $75+$ & $1.90[1.88,1.92]$ & $1.03[1.01,1.05]$ \\
\hline \multicolumn{3}{|l|}{ Gender } \\
\hline Female & Reference & Reference \\
\hline Male & $1.19[1.18,1.20]$ & $1.27[1.26,1.28]$ \\
\hline \multicolumn{3}{|l|}{ Race } \\
\hline White & Reference & Reference \\
\hline Black & $0.91[0.90,0.92]$ & $0.85[0.83,0.86]$ \\
\hline Hispanic & $0.80[0.78,0.82]$ & $0.79[0.76,0.81]$ \\
\hline Other & $0.99[0.98,1.00]$ & $0.96[0.95,0.98]$ \\
\hline \multicolumn{3}{|l|}{ Marital status } \\
\hline Married & Reference & Reference \\
\hline Single & $1.57[1.55,1.59]$ & $1.43[1.42,1.45]$ \\
\hline Unknown/other & $1.41[1.39,1.43]$ & $1.27[1.24,1.29]$ \\
\hline \multicolumn{3}{|l|}{ Primary insurance } \\
\hline Private (commercial) & Reference & Reference \\
\hline Medicaid & $2.13[2.09,2.17]$ & $1.84[1.80,1.88]$ \\
\hline Medicare managed & $2.35[2.31,2.39]$ & $1.98[1.93,2.03]$ \\
\hline Medicare traditional & $2.65[2.61,2.69]$ & $2.09[2.04,2.13]$ \\
\hline Self-pay or other & $1.41[1.38,1.44]$ & $1.26[1.23,1.29]$ \\
\hline \multicolumn{3}{|l|}{ Admitting department } \\
\hline Surgical & Reference & Reference \\
\hline Nonsurgical & $1.06[1.05,1.07]$ & $1.05[1.03,1.06]$ \\
\hline Any ICU stay & $2.05[2.03,2.07]$ & $1.53[1.51,1.55]$ \\
\hline Mechanical ventilation & $3.22[3.18,3.26]$ & $1.84[1.81,1.87]$ \\
\hline \multicolumn{3}{|l|}{ Diagnoses } \\
\hline Delirium & $5.48[5.42,5.45]$ & $2.93[2.88,2.98]$ \\
\hline Dementia & $5.21[5.15,5.27]$ & $2.78[2.72,2.83]$ \\
\hline Insomnia & $1.72[1.67,1.78]$ & $1.51[1.45,1.57]$ \\
\hline \multicolumn{3}{|l|}{ NNo. of beds } \\
\hline$\leq 200$ & Reference & Reference \\
\hline $201-300$ & $1.01[0.99,1.03]$ & $0.96[0.94,0.98]$ \\
\hline $301-500$ & $0.98[0.97,1.00]$ & $0.93[0.91,0.95]$ \\
\hline $500+$ & $0.97[0.96,0.98]$ & $0.91[0.90,0.93]$ \\
\hline \multicolumn{3}{|l|}{ Population served } \\
\hline Urban & Reference & Reference \\
\hline Rural & $0.96[0.95,0.98]$ & $0.91[0.89,0.93]$ \\
\hline \multicolumn{3}{|l|}{ Teaching status } \\
\hline Teaching & Reference & Reference \\
\hline Nonteaching & $1.03[1.02,1.04]$ & $0.98[0.97,1.00]$ \\
\hline \multicolumn{3}{|l|}{ US Census region } \\
\hline West & Reference & Reference \\
\hline Northeast & $1.03[1.01,1.05]$ & $1.04[1.02,1.06]$ \\
\hline Midwest & $0.95[0.94,0.97]$ & $0.93[0.91,0.94]$ \\
\hline South & $1.02[1.01,1.03]$ & $1.07[1.05,1.09]$ \\
\hline
\end{tabular}

NOTE: Abbreviations: $\mathrm{Cl}$, confidence interval; ICU, intensive care unit; RR, relative risk. "Adjusted RR derived using a generalized estimating equation with a Poisson error term, a log link, and an exchangeable correlation structure to account for repeated admissions of the same patient during the study, simultaneously including all characteristics above as independent variables.

demonstrated delirium to be the most common reason for antipsychotic initiation in hospitalized patients, ${ }^{12,18}$ an indication for which efficacy/effectiveness data are lacking. A recent systematic review of antipsychotics for the treatment of delirium in older adults concluded that because of severe methodological limitations, the small number of existing studies on this topic do not support the use of antipsychotics in the treatment of delirium in older hospitalized adults. ${ }^{19}$ Our results fur- ther highlight the need for randomized placebocontrolled trials of antipsychotics in treatment of delirium.

We found variation in antipsychotic use between hospitals that was not fully explained by patient characteristics. Insufficient data to inform clinical decisions surrounding management of agitated delirium/dementia and lack of clear criteria by which to judge appropriateness of antipsychotic use may contribute to this variation. Some variation may relate to resource allocation at different hospitals, and the feasibility of implementing nonpharmacologic management options across settings. Our results collectively highlight the need for studies evaluating the efficacy/effectiveness of antipsychotics in the treatment of delirium and drivers of physician decision-making in this realm, as well as the need for greater hospital investment in nonpharmacologic delirium-prevention programs, which have been shown to be effective in prevention of delirium in hospitalized patients. ${ }^{20}$

We observed high levels of potentially excessive daily dosing using cutoffs applied in the long-term care setting. The majority of the potentially excessive doses were in the setting of typical antipsychotic use, and haloperidol specifically, where doses exceeded 4 $\mathrm{mg}$ on at least 1 day in $87 \%$ of exposed admissions. Of note, the threshold for haloperidol dosage above which justification is required was decreased from 4 to $2 \mathrm{mg}$ per day in the 2015 update to the CMS guidelines. ${ }^{21}$ For the present analysis, we used the guidelines that were contemporaneous to our cohort; we are unable to determine current rates of potentially inappropriate dosages in the present analysis, but given the high prevalence in 2009 to 2010, and the lowering of the dosage threshold since then, it is unlikely that any decrease in use would be enough to substantially reduce the estimate. Whether these high dosages are actually inappropriate in the hospital setting is not established, and we were not able to review medical records to determine whether justification for use of such doses was documented. ${ }^{22,23}$ It is possible that hospitalized patients with altered pharmacodynamics and greater severity of illness could require larger doses of these medications; however, this is an area in need of further investigation, and current critical care guidelines note the lack of sufficient data upon which to justify use of haloperidol in the prevention or treatment of delirium in ICU patients. ${ }^{24,25}$

The dosages in use are concerning given that the risk of extrapyramidal side effects increases with increasing dose, and prior studies have demonstrated an association between increased dose of antipsychotics and increased risk of other adverse events, including hip fracture and sudden cardiac death..$^{22,23}$ Further, despite these known risks, studies have demonstrated failure to follow recommendations to mitigate risk, ${ }^{26}$ such as electrocardiogram monitoring in individuals receiving intravenous haloperidol. ${ }^{27}$ Our 


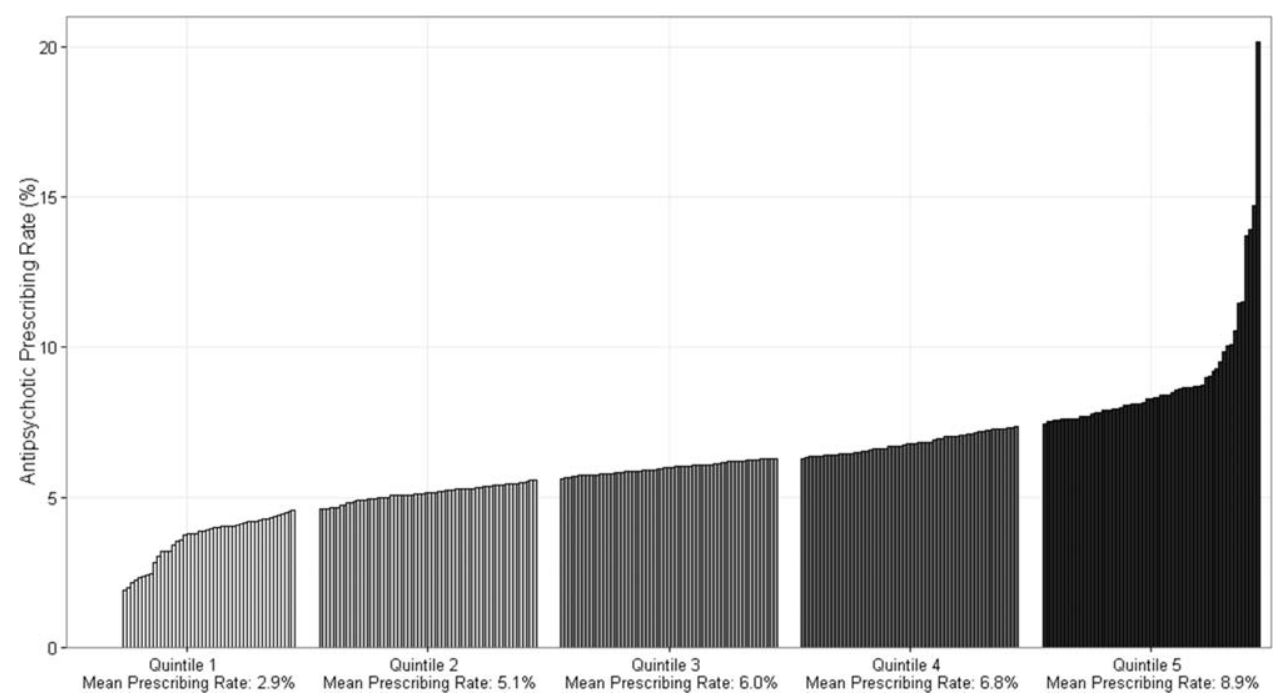

FIG. 1. Hospital antipsychotic prescribing rates. Bars represent the percentage of admissions exposed to an antipsychotic at each hospital in our cohort, divided into the corresponding hospital prescribing quintiles.

results suggest that physicians are similarly not following recommendations to use lower doses of haloperidol when treating older patients, given the almost identical incidence of potentially excessive dosing among admissions of patients aged 65 years and older in our cohort. ${ }^{25}$ Clinical decision support prompts have been effective at increasing appropriate use of antipsychotic medications in several single-center analyses, ${ }^{28-30}$ and widespread implementation of such support with a focus on haloperidol dosing should be considered on the basis of our results.

The patient characteristics associated with antipsychotic use in this large, nationally representative analysis are consistent with those identified in prior singlecenter analyses. ${ }^{12,18}$ Both prior analyses identified delirium as the most common reason for antipsychotic use, and dementia, intensive care unit stay, and mechanical ventilation were also previously identified as strong predictors of use that we believe hold face validity for the practicing hospitalist. On the other hand, some of the factors associated with antipsychotic use in our model cannot be readily explained, such as insurance status and race, and may be serving as proxies for other variables not included in our analysis. That nonwhite patients are less likely than white patients to receive antipsychotic medications in the hospital has been previously demonstrated, ${ }^{12}$ and further investigation to understand this disparity is warranted.

Our study has several additional limitations. First, because our study is observational, the possibility of residual confounding exists, and we cannot rule out that there are other patient factors driving the hospital variation in antipsychotic use that we observed. Second, because guidelines do not exist for antipsychotic dosing in hospitalized patients, we could only comment on "potentially" excessive dosing, extrapolating from guidelines in the long-term care setting. Whether
TABLE 4. Relative Risk of Antipsychotic Exposure for Admissions Within Each Hospital Prescribing Quintile, Overall, and Stratified by Delirium and Dementia

\begin{tabular}{cccc}
\hline & $\begin{array}{c}\text { Admissions, } \\
\text { No. (\% of Total) }\end{array}$ & $\begin{array}{c}\text { Unadjusted RR of } \\
\text { Exposure [95\% Cl] }\end{array}$ & $\begin{array}{c}\text { Adjusted RR of } \\
\text { exposure }[95 \% \mathrm{Cl}]^{*}\end{array}$ \\
\hline Overalli & & & \\
Q1 & $431,017(16 \%)$ & Reference & Reference \\
Q2 & $630,486(23 \%)$ & $1.67[1.63,1.71]$ & $1.59[1.55,1.62]$ \\
$Q 3$ & $548,337(20 \%)$ & $1.93[1.88,1.97]$ & $1.84[1.80,1.88]$ \\
Q4 & $639,027(24 \%)$ & $2.16[2.12,2.21]$ & $2.07[2.03,2.12]$ \\
Q5 & $446,214(17 \%)$ & $2.83[2.77,2.89]$ & $2.56[2.50,2.61]$ \\
Delirium & & & \\
Q1 & $12,878(15 \%)$ & Reference & Reference \\
Q2 & $20,588(24 \%)$ & $1.58[1.51,1.65]$ & $1.58[1.51,1.65]$ \\
Q3 & $17,402(20 \%)$ & $1.71[1.64,1.80]$ & $1.73[1.65,1.82]$ \\
Q4 & $20,943(24 \%)$ & $2.01[1.92,2.10]$ & $1.99[1.91,2.08]$ \\
Q5 & $14,883(17 \%)$ & $2.15[2.05,2.25]$ & $2.16[2.07,2.26]$ \\
Dementia & & & \\
Q1 & $28,290(15 \%)$ & Reference & Reference \\
Q2 & $42,018(22 \%)$ & $1.43[1.36,1.50]$ & $1.40[1.34,1.47]$ \\
Q3 & $38,593(21 \%)$ & $1.61[1.53,1.69]$ & $1.59[1.51,1.66]$ \\
Q4 & $44,638(24 \%)$ & $1.69[1.62,1.77]$ & $1.69[1.61,1.77]$ \\
Q5 & $34,442(18 \%)$ & $1.92[1.83,2.01]$ & $1.90[1.81,1.99]$ \\
\hline
\end{tabular}

NOTE: Abbreviations: $\mathrm{Cl}$, confidence interval; $\mathrm{Q}$, quintile; RR, relative risk. " $A d j$ justed for all patient characteristics listed in Table 1 (except discharge disposition), as well as the Elixhauser comorbidities, using a generalized estimating equation with a Poisson error term, a log link, and an exchangeable correlation structure to account for repeated admissions of the same patient during the study. $\dagger$ Antipsychotic prescribing rates for hospitals within each quintile were: Q1: <4.6\%, Q2: 4.6\%-5.6\%, Q3: $5.7 \%-6.3 \%$, Q4: 6.4\%-7.4\%, Q5: $>7.4 \%$.

such doses are actually excessive in hospitalized patients is not defined. Third, although Premier performs quality checks on charge and ICD-9-CM coding data submitted by participating hospitals, the validity of administrative data is uncertain. For example, the use of administrative data to identify delirium diagnoses is likely to have resulted in underestimation of delirium incidence among our different exposure groups. Delirium is likely to be coded more often in the setting of more severe or hyperactive cases, when 
antipsychotics are more likely to be utilized. This could result in an overestimation of the association between delirium and antipsychotic use. Additionally, differences in coding practices between hospitals for any of the variables in our models could explain some of the variation in antipsychotic prescribing that we observed. Finally, because we were unable to differentiate between new initiation and continuation of a preadmission antipsychotic, some of the variation that we observed is likely to reflect differences in outpatient antipsychotic prescribing practices.

In conclusion, in this large cohort of nonpsychiatric admissions to 300 US hospitals, we found that antipsychotic medication exposure was common, often at high daily doses. Delirium and dementia were the strongest predictors of use among the patient and hospital characteristics examined. The variation in antipsychotic prescribing that we observed was not fully accounted for by measured patient characteristics, and raises the possibility of differing hospital prescribing cultures. Our results draw attention to the need for additional research to better define what constitutes appropriate use of these potentially harmful medications in the hospital setting.

Disclosures: Dr. Herzig had full access to all of the data in the study and takes responsibility for the integrity of the data and the accuracy of the data analysis. Study concept and design: Drs. Herzig, Rothberg, Gurwitz, and Marcantonio. Acquisition of data: Dr. Herzig. Analysis of data: Mr. Guess. Interpretation of data: Drs. Herzig, Rothberg, Gurwitz, Marcantonio, and Mr. Guess. Drafting of the manuscript: Dr. Herzig. Critical revision of the manuscript for important intellectual content: Drs. Rothberg, Gurwitz, Marcantonio, and Mr. Guess. Dr. Herzig was funded by grant number K23AG042459 from the National Institute on Aging. Dr. Marcantonio was funded by grant number K24AG035075 from the National Institute on Aging. The funding organizations had no involvement in any aspect of the study, including design and conduct of the study; collection, management, analysis, and interpretation of the data; and preparation, review, or approval of the manuscript. The authors report no conflicts of interest.

\section{References}

1. Rochon PA, Stukel TA, Bronskill SE, et al. Variation in nursing home antipsychotic prescribing rates. Arch Intern Med. 2007;167(7):676683.

2. Inouye SK, Charpentier PA. Precipitating factors for delirium in hospitalized elderly persons. Predictive model and interrelationship with baseline vulnerability. JAMA. 1996;275(11):852-857.

3. Inouye SK, Viscoli CM, Horwitz RI, Hurst LD, Tinetti ME. A predictive model for delirium in hospitalized elderly medical patients based on admission characteristics. Ann Intern Med. 1993;119(6): 474-481.

4. Pompei P, Foreman M, Rudberg MA, Inouye SK, Braund V, Cassel CK. Delirium in hospitalized older persons: outcomes and predictors. J Am Geriatr Soc. 1994;42(8):809-815.

5. McPherson K, Wennberg JE, Hovind OB, Clifford P. Small-area variations in the use of common surgical procedures: an international comparison of New England, England, and Norway. N Engl J Med. 1982; 307(21):1310-1314.

6. Premier Research Services. Available at: https://www.premierinc.com/ transforming-healthcare/healthcare-performance-improvement/premierresearch-services. Accessed March 15, 2016.

7. U.S. Food and Drug Administration. Atypical antipsychotic drugs information. Available at: http://www.fda.gov/drugs/drugsafety/postmarketdrugsafetyinformationforpatientsandproviders/ucm094303.htm. Accessed November 1, 2015.
8. U.S. Food and Drug Administration. Information on conventional antipsychotics. Available at: http://www.fda.gov/drugs/drugsafety/ postmarketdrugsafetyinformationforpatientsandproviders/ucm107211. htm. Accessed November 1, 2015.

9. Centers for Medicare and Medicaid Services. State Operations Manual. Appendix PP: guidance to surveyors for long-term care facilities. Available at: https://www.cms.gov/Medicare/Provider-Enrollmentand-Certification/GuidanceforLawsAndRegulations/Downloads/som107 ap_pp_guidelines_ltcf.pdf. Revised October 14, 2005. Accessed March $15,2016$.

10. Zou G. A modified Poisson regression approach to prospective studies with binary data. Am J Epidemiol. 2004;159(7):702-706.

11. Healthcare Cost and Utilization Project. Comorbidity software, version 3.7. Agency for Healthcare Research and Quality, Rockville, MD. Available at: http://www.hcup-us.ahrq.gov/toolssoftware/ comorbidity/comorbidity.jsp. Accessed March 15, 2016.

12. Herzig SJ, Rothberg MB, Guess JR, et al. Antipsychotic use in hospitalized adults: rates, indications, and predictors. J Am Geriatr Soc. 2016;64(2):299-305.

13. Weiss AJ, Elixhauser A. Overview of hospital stays in the United States, 2012. HCUP Statistical Brief \#180. Agency for Healthcare Research and Quality, Rockville, MD. Available at: http://www.hcup-us.ahrq. gov/reports/statbriefs/sb180-Hospitalizations-United-States-2012.pdf. Published October 2014. Accessed June 29, 2015.

14. Harris-Kojetin L, Sengupta M, Park-Lee E, Valverde R. Long-term care services in the United States: 2013 overview. Vital Health Stat 3. 2013;(37):1-107. Available at: http://www.cdc.gov/nchs/data/nsltcp/ long_term_care_services_2013.pdf. Accessed March 16, 2016.

15. Briesacher BA, Limcangco MR, Simoni-Wastila L, et al. The quality of antipsychotic drug prescribing in nursing homes. Arch Intern Med. 2005;165(11):1280-1285.

16. Chen Y, Briesacher BA, Field TS, Tjia J, Lau DT, Gurwitz JH. Unexplained variation across US nursing homes in antipsychotic prescribing rates. Arch Intern Med. 2010;170(1):89-95.

17. Crystal S, Olfson M, Huang C, Pincus H, Gerhard T. Broadened use of atypical antipsychotics: safety, effectiveness, and policy challenges. Health Aff (Millwood). 2009;28(5):w770-w781.

18. Loh KP, Ramdass S, Garb JL, Brennan MJ, Lindenauer PK, Lagu T. From hospital to community: use of antipsychotics in hospitalized elders. J Hosp Med. 2014;9(12):802-804.

19. Flaherty JH, Gonzales JP, Dong B. Antipsychotics in the treatment of delirium in older hospitalized adults: a systematic review. J Am Geriatr Soc. 2011;59(suppl 2):S269-S276.

20. Hshieh TT, Yue J, Oh E, et al. Effectiveness of multicomponent nonpharmacological delirium interventions: a meta-analysis. JAMA Intern Med. 2015;175(4):512-520.

21. Centers for Medicare and Medicaid Services. State operations manual, appendix PP: guidance to surveyors for long-term care facilities. Available at: https://www.cms.gov/Regulations-and-Guidance/Guidance/ Manuals/downloads/som107ap_pp_guidelines_ltcf.pdf. Revised October 9,2015. Accessed February 22, 2016.

22. Ray WA, Griffin MR, Schaffner W, Baugh DK, Melton LJ III. Psychotropic drug use and the risk of hip fracture. N Engl J Med. 1987; 316(7):363-369.

23. Ray WA, Chung CP, Murray KT, Hall K, Stein CM. Atypical antipsychotic drugs and the risk of sudden cardiac death. N Engl J Med. 2009;360(3):225-235.

24. Barr J, Fraser GL, Puntillo K, et al. Clinical practice guidelines for the management of pain, agitation, and delirium in adult patients in the intensive care unit. Crit Care Med. 2013;41(1):263-306.

25. Zirker W, Dorokhine I, Knapp CM, Patel N, Musuku M. Haloperidol overdosing in the treatment of agitated hospitalized older people with delirium: a retrospective chart review from a community teaching hospital. Drugs Aging. 2013;30(8):639-644.

26. Cheung D, Wolfe B, Wald $\mathrm{H}$, Cumbler $\mathrm{E}$. Unsafe use of intravenous haloperidol: evaluation of recommendation-concordant care in hospitalized elderly adults. J Am Geriatr Soc. 2013;61(1):160-161.

27. U.S. Food and Drug Administration. HALDOL brand of haloperidol injection. Available at: http://www.accessdata.fda.gov/drugsatfda docs/label/2008/015923s082,018701s057lbl.pdf. Accessed February $23,2016$.

28. Mattison ML, Afonso KA, Ngo LH, Mukamal KJ. Preventing potentially inappropriate medication use in hospitalized older patients with a computerized provider order entry warning system. Arch Intern Med. 2010;170(15):1331-1336.

29. Mattison ML, Catic A, Davis RB, et al. A standardized, bundled approach to providing geriatric-focused acute care. J Am Geriatr Soc. 2014;62(5):936-942.

30. Pell JM, Cheung D, Jones MA, Cumbler E. Don't fuel the fire: decreasing intravenous haloperidol use in high risk patients via a customized electronic alert. J Am Med Inform Assoc. 2014;21(6):1109-1112. 